\title{
nALL
}

Citeerwijze van dit artikel:

Rolf Ortlep, 'Het arrest Byankov: specifieke Unierechtelijke plicht tot heroverweging van een in rechte onaantastbaar besluit', NALL 2013, juli-september, DOI: 10.5553/NALL/.000012

\section{Het arrest Byankov: specifieke Unierechtelijke plicht tot heroverweging van een in rechte onaantastbaar besluit}

\author{
Rolf Ortlep
}

\section{Inleiding}

Op 4 oktober 2012 heeft het Hof van Justitie uitspraak gedaan in de zaak Byankov. ${ }^{1}$ Aan Byankov is bij besluit een verbod opgelegd om het grondgebied van Bulgarije te verlaten. Uit het prejudicieel antwoord van het Hof blijkt dat dit verbod onverenigbaar is met richtlijn 2004/38/EG en met het door artikel 21 Verdrag betreffende de werking van de Europese Unie (hierna: VWEU) verleende recht op vrij verkeer en verblijf van Unieburgers. Mede vanwege deze kennelijke onverenigbaarheid en omdat dit verbod absoluut en voor onbepaalde tijd geldt, beslist het Hof dat de nationale onmogelijkheid om het besluit te heroverwegen ${ }^{2}$ niet wordt gerechtvaardigd door het rechtszekerheidsbeginsel en in die mate in strijd is met het doeltreffendheidsbeginsel en het beginsel van loyale samenwerking ex artikel 4, lid 3, Verdrag betreffende de Europese Unie (hierna: VEU). De vraag is hoe dit geplaatst moet worden in het licht van eerdere jurisprudentie van het Hof, waarin het uitgangspunt is neergelegd dat, bij een gebrek aan een Unierechtelijke regeling dienaangaande, het EU-recht er niet toe verplicht dat een met dat recht strijdig in rechte onaantastbaar besluit wordt heroverwogen. Deze vraag staat in de onderhavige bijdrage centraal.

\section{Feiten}

Bij besluit van 17 april 2007 heeft de directeur van het regionale directoraat van het Bulgaarse ministerie van Binnenlandse zaken aan Byankov een verbod opgelegd om het Bulgaarse grondgebied te verlaten, aangezien hij een aanzienlijke schuld heeft jegens een privaatrechtelijke rechtspersoon. Dit besluit is niet door Byankov aangevochten en is daarom in rechte onaantastbaar. Op 6 juli 2010 heeft Byankov verzocht om het besluit te heroverwegen. In dat licht is artikel 99 van de Administrativnoprotsesualenkodeks (wetboek inzake het bestuursprocesrecht; hierna: APK) van belang. Hierin is het volgende bepaald:

Een definitief geworden individueel of algemeen bestuursbesluit dat niet voor de rechter is aangevochten, kan door het onmiddellijk hiërarchisch hogere bestuursorgaan, of indien het bestuursbesluit niet bestuursrechtelijk kon worden aangevochten, door het orgaan dat het besluit heeft genomen, worden 
ingetrokken of gewijzigd indien:

1. een wezenlijke schending van een van de voorwaarden voor de rechtmatigheid ervan is begaan; [...]

7. bij een uitspraak van het Europees Hof voor de rechten van de mens een schending van het Europees Verdrag tot bescherming van de rechten van de mens en de fundamentele vrijheden is vastgesteld.

Krachtens de artikelen 100 en 102, lid 1, APK kan de bevoegdheid van artikel 99 APK alleen worden uitgeoefend binnen de maand na de vaststelling van het betrokken besluit en op initiatief van het bestuursorgaan dat het besluit heeft vastgesteld, dan wel van de betrokken procureur of van de ombudsman. Verder kan volgens artikel 102, lid 2, APK in het in artikel 99, lid 7, APK bedoelde geval de procedure worden heropend op verzoek van de adressaat.

Het verzoek van 6 juli 2010 om het besluit van 17 april 2007 te heroverwegen wordt op 20 juli 2010 afgewezen, omdat geen van de in artikel 99, leden 2 tot en met 7, APK neergelegde gronden voor heroverweging aan de orde was. Tevens is er geen sprake van de in artikel 99, lid 1, APK bedoelde grond voor heroverweging, daar binnen de vastgestelde termijn geen verzoek is ingediend door een daartoe bevoegde. Byankov heeft daarop bij de verwijzende rechter beroep ingesteld, waar hij heeft gevorderd dat het besluit van 20 juli 2010 nietig wordt verklaard, en dat zijn verzoek tot heroverweging van het besluit van 17 april 2007 wordt toegewezen.

\section{Vrij verkeer en verblijf van Unieburgers}

Uit het prejudicieel antwoord van het Hof van Justitie volgt dat het verbod aan Byankov om het Bulgaarse grondgebied te verlaten onverenigbaar is met richtlijn 2004/38/EG 3 en met het door artikel 21 VWEU verleende recht op vrij verkeer en verblijf van Unieburgers. Het Hof onderbouwt deze onverenigbaarheid met dat niet kan worden uitgesloten dat het besluit louter een economisch oogmerk heeft, te weten de bescherming van schuldeisers, terwijl het vrij verkeer volgens richtlijn 2004/38/EG uitsluitend kan worden beperkt om redenen van openbare orde, openbare veiligheid en volksgezondheid, en juist niet om economische redenen. Verder is een dergelijk verbod naar het oordeel van het Hof in strijd met het in die richtlijn gecodificeerde evenredigheidsbeginsel, daar het absoluut is. Het verbod kent namelijk 'geen uitzonderingen, geen begrenzing in de tijd en geen mogelijkheid tot een regelmatig heronderzoek van de feitelijke en juridische omstandigheden waarop het is gebaseerd'. Daarenboven bevat het Unierecht andere rechtsnormen ter bescherming van de rechten van schuldeisers. ${ }^{4}$ Als gevolg hiervan gaat het verbod om het grondgebied te verlaten verder dan ter bereiking van het nagestreefde doel - de bescherming van schuldeisers - noodzakelijk is. 5 Het Hof concludeert 'dat het Unierecht aldus moet worden uitgelegd dat het zich verzet tegen de toepassing van een nationale bepaling die voorziet in de oplegging van een beperking van het recht van een staatsburger van een lidstaat om vrij te reizen binnen de Unie louter omdat hij jegens een privaatrechtelijke rechtspersoon een geldschuld heeft'.

\section{Unierechtelijke plicht tot heroverweging}

\subsection{Inleiding}

Nadat het Hof van Justitie het bovenstaande heeft geconcludeerd, komt het toe 
aan de vraag of naar Unierecht het in rechte onaantastbare uitreisverbod van 17 april 2007 heroverwogen moet worden. Voor een goed begrip van de beantwoording door het Hof van deze vraag is het van belang om hieronder tevens de eerdere relevante jurisprudentie op het netvlies te krijgen. ${ }^{6}$

In zijn jurisprudentie heeft het Hof van Justitie het uitgangspunt neergelegd dat, bij een gebrek aan een Unierechtelijke regeling dienaangaande, het EU-recht er niet toe verplicht dat een met dat recht strijdig in rechte onaantastbaar besluit wordt heroverwogen. Dit uitgangspunt is als eerste geformuleerd in het Kühne \& Heitz-arrest. ${ }^{7}$ In dat arrest heeft het Hof vervolgens de volgende vier voorwaarden geformuleerd wanneer het bestuursorgaan krachtens het in artikel 4, lid 3, VEU vervatte beginsel van loyale samenwerking verplicht is om zijn in rechte onaantastbaar besluit te heroverwegen:

1) het bestuursorgaan is naar nationaal recht bevoegd om zijn in rechte onaantastbaar besluit te heroverwegen;

2) dat besluit is in rechte onaantastbaar ten gevolge van een uitspraak van een nationale rechterlijke instantie waarvan de beslissingen niet vatbaar zijn voor een gewoon rechtsmiddel;

3) voormelde uitspraak berust, gelet op latere rechtspraak van het Hof, op een onjuiste uitleg van het EU-recht, gegeven zonder dat het Hof overeenkomstig artikel 267 VWEU is verzocht om een prejudiciële beslissing, en

4) een betrokkene heeft zich tot het bestuursorgaan gewend onmiddellijk na van die rechtspraak kennis te hebben genomen.

In de zaak Byankov overweegt het Hof van Justitie al snel dat het Kühne \& Heitz-arrest niet direct relevant is, aangezien Byankov tegen het uitreisverbod van 17 april 2007 geen beroep bij de rechter heeft ingesteld, en dat besluit dus niet in rechte onaantastbaar is ten gevolge van een uitspraak van een nationale rechterlijke instantie waarvan de beslissingen niet vatbaar zijn voor een gewoon rechtsmiddel. Hetzelfde was het geval in het i-21 \& Arcor-arrest; deze twee bedrijven hadden ook geen beroep ingesteld tegen de aan hen gerichte ongevallige besluiten. 'Bijgevolg is', aldus het Hof in dat arrest, 'het reeds aangehaalde arrest Kühne \& Heitz niet relevant om te bepalen of in een situatie als aan de orde in de hoofdgedingen, een bestuursorgaan verplicht is om definitief geworden besluiten opnieuw te onderzoeken' ${ }^{\mathbf{8}}$ Ondanks het feit dat in het i-21 \& Arcor-arrest niet aan de vier voorwaarden uit het Kühne \& Heitzarrest was voldaan, bezag het Hof in het kader van de beginselen van loyale samenwerking (ex artikel 4, lid 3, VEU) en nationale procedurele autonomie de vraag in hoeverre op grond van de beginselen van gelijkwaardigheid en effectiviteit het EU-recht verplicht dat een met dat recht strijdig in rechte onaantastbaar besluit werd heroverwogen. Op grond daarvan heb ik geconcludeerd dat deze vraag niet, althans niet uitsluitend, beantwoord moet worden aan de hand van de vier voorwaarden uit het Kühne \& Heitz-arrest.9 Zoals hieronder uiteen wordt gezet, is het arrest Byankov een bevestiging van deze conclusie.

Uit het arrest Byankov volgt dat het Hof van Justitie van oordeel is dat de vraag of het EU-recht verplicht tot heroverweging van een met dat recht strijdig in rechte onaantastbaar besluit in algemene zin beantwoord moet worden binnen het kader van de beginselen van loyale samenwerking (ex artikel 4, lid 3, VEU) en nationale procedurele autonomie, waarbij de beginselen van gelijkwaardigheid en effectiviteit de randvoorwaarden zijn waaraan het nationale recht moet voldoen. De wijze waarop het EU-recht ten uitvoer wordt 
gelegd, is, bij een gebrek aan een Unierechtelijke regeling dienaangaande, een zaak van de rechtsorde van de lidstaten. Dit staat bekend als het beginsel van nationale procedurele autonomie. Met betrekking tot dat beginsel gelden bepaalde minimumvereisten; vereisten die tot uitdrukking komen in het gelijkwaardigheids- en het effectiviteitsbeginsel. Het gelijkwaardigheidsbeginsel vereist dat voor een vordering waarbij het EU-recht wordt ingeroepen de regels van nationaal recht niet ongunstiger mogen zijn dan voor een vergelijkbare vordering die enkel gebaseerd is op nationaal recht. Het effectiviteitsbeginsel (doeltreffendheidsbeginsel) vereist dat de rechtsregels van het nationale recht de uitoefening van rechten die gebaseerd zijn op het EU-recht niet uiterst moeilijk of praktisch onmogelijk maken. ${ }^{\mathbf{1 0}}$

\subsection{Gelijkwaardigheidsbeginsel}

Wat betreft het gelijkwaardigheidsbeginsel is het Hof van Justitie kort. Er kan door het Hof niet worden vastgesteld of dat beginsel geschonden is, aangezien de verwijzende rechter geen woord heeft gezegd over het feit dat de toepassing van de in artikel 99 APK voorziene voorwaarden voor de heroverweging van een in rechte onaantastbaar besluit kan verschillen naargelang de onrechtmatigheid van dat besluit wordt gebaseerd op schending van het Unierecht dan wel van het nationale recht. ${ }^{\mathbf{1 1}}$ In de marge zij opgemerkt dat het Hof geen punt maakt van het feit dat in artikel 99, lid 7, APK de bevoegdheid is opgenomen om een in rechte onaantastbaar besluit te heroverwegen indien bij een arrest van het EHRM een schending van het EVRM is vastgesteld. Voor onder meer Nederland is dit van belang, omdat er krachtens artikel 457, lid 1 en onder 3, Wetboek van Strafvordering (hierna: Sv) de mogelijkheid tot herziening van een in kracht van gewijsde gegane einduitspraak bestaat indien een uitspraak van het EHRM inhoudt dat het EVRM is geschonden in de procedure die tot de veroordeling heeft geleid. ${ }^{\mathbf{1 2}}$ In het licht daarvan is door L.A.D. Keus betoogd dat het niet uitgesloten is dat het Hof van Justitie in het verlengde van het gelijkwaardigheidsbeginsel zou oordelen dat voor de vaststelling door het Hof dat het Unierecht is geschonden een vergelijkbare herzieningsmogelijkheid als artikel 457, lid 1 en onder 3 , Sv gecreëerd moet worden. ${ }^{\mathbf{1 3}}$ Dat het Hof tot een dergelijk oordeel komt lijkt uitgesloten te zijn. ${ }^{\mathbf{1 4}}$ Met A-G Mengozzi kan in zijn conclusie voor het Byankov-arrest allereerst worden opgemerkt dat het vraagstuk van het heroverwegen van een in rechte onaantastbaar besluit respectievelijk rechterlijke uitspraak bij schending van het Unierecht van een andere aard is dan het geval is bij schending van het EVRM. A-G Mengozzi:

"[...] het Unierecht [heeft], in tegenstelling tot het recht van het EVRM, twee essentiële kenmerken [...], te weten voorrang en rechtstreekse werking. Voorts heeft het Hof er herhaaldelijk op gewezen dat "(d)e uitlegging die het Hof krachtens de hem bij artikel (267 VWEU) verleende bevoegdheid aan een voorschrift van het (Unie)recht geeft, de betekenis en de strekking van dat voorschrift zoals het sedert het tijdstip van zijn inwerkingtreding moet of had moeten worden verstaan en toegepast, zo nodig verklaart en preciseert". Gelet op de specifieke kenmerken van de rechtsorde van de Unie en de bijzondere aard van het mechanisme van de prejudiciële verwijzing moeten de verplichtingen die op de nationale rechterlijke instanties rusten inzake de voorwaarden waaronder zij de rechtmatigheid van een definitief geworden bestuursbesluit wegens schending van Unierecht moeten herbezien, geheel anders worden gezien dan in de situatie waarin de beweerde onrechtmatigheid voortvloeit uit een arrest van het Europese Hof voor de rechten van de 
mens."15

Ook P.H.P.H.M.C. van Kempen heeft betoogd dat het vraagstuk van het heroverwegen van een in rechte onaantastbaar besluit respectievelijk rechterlijke uitspraak bij schending van het Unierecht van een andere aard is dan het geval is bij schending van het EVRM. ${ }^{\mathbf{1 6}}$ Een argument dat hij hiervoor heeft genoemd is dat er een verschil bestaat betreffende 'de aard en het doel van de rechten waarvan de burger bescherming zoekt: het EVRM ziet op individuele fundamentele rechten (of zo men wil: mensenrechten), terwijl dat in beginsel en in elk geval in zijn algemeenheid niet het geval is voor het Europees recht'. ${ }^{17}$ Het laatste is evenwel veranderd doordat met de inwerkingtreding van het Verdrag van Lissabon het Handvest van de grondrechten van de Europese Unie, waarin onder meer de mensenrechten die gewaarborgd zijn door het EVRM onderschreven zijn, krachtens artikel 6, lid 1, VEU dezelfde juridische waarde hebben gekregen als het VEU en VWEU. ${ }^{\mathbf{1 8}}$ Anders gezegd, het handvest en daarmee de mensenrechten die ook gewaarborgd zijn door het EVRM zijn aan te merken als primair EU-recht met een status die gelijk is aan die van het VEU en VWEU. Dit brengt enigszins een nuancering aan op het - hierboven weergegeven - standpunt van A-G Mengozzi dat het Unierecht in tegenstelling tot het recht van het EVRM twee essentiële kenmerken heeft, te weten voorrang

en rechtstreekse werking. ${ }^{19}$ Het voorgaande sluit evenwel niet in dat het Hof van Justitie in het verlengde van het gelijkwaardigheidsbeginsel zou oordelen dat voor de vaststelling door het Hof dat het Unierecht is geschonden een vergelijkbare herzieningsmogelijkheid als artikel 457, lid 1 en onder 3, Sv gecreëerd moet worden. Het Hof heeft namelijk meermaals geoordeeld dat indien naar nationaal recht geen bevoegdheid bestaat om een in rechte onaantastbaar besluit respectievelijk rechterlijke uitspraak te heroverwegen, er vanuit het EU-recht geen plicht bestaat om een dergelijke bevoegdheid te creëren als in strijd met dat recht is gehandeld. ${ }^{\mathbf{2 o}}$

\subsection{Effectiviteitsbeginsel}

Nadat het Hof van Justitie in het licht van het gelijkwaardigheidsbeginsel de vraag heeft besproken of het EU-recht verplicht tot heroverweging van een met dat recht strijdig in rechte onaantastbaar besluit, komt het ter zake toe aan het effectiviteitsbeginsel (in samenhang met het beginsel van loyale samenwerking ex artikel 4, lid 3, VEU). Het past daarbij de procedurele rule-of-reason-toets toe. Deze toets is door het Hof ontwikkeld om antwoord te geven op de vraag of een nationale rechtsregel voldoet aan het effectiviteitsbeginsel. Er dient een belangenafweging te worden gemaakt tussen dat beginsel en de achtergrond van een nationale rechtsregel. Bij deze belangenafweging spelen de volgende factoren een rol: de plaats van de betreffende nationale rechtsregel in de gehele procedure; het verloop en de bijzondere kenmerken ervan, en de beginselen die meer algemeen aan het nationale stelsel van rechtspraak ten grondslag liggen, zoals het rechtszekerheidsbeginsel en het goede verloop van de procedure. ${ }^{\mathbf{2 1}}$ In het arrest Byankov ziet het Hof zich voor de vraag gesteld of het rechtszekerheidsbeginsel als achterliggend beginsel van het beperkte regiem van de heroverwegingsmogelijkheid van artikel 99 APK, in het licht van het effectiviteitsbeginsel, een legitieme rechtvaardiging is. Het Hof herhaalt allereerst zijn overweging uit onder meer zijn - hierboven besproken - Kühne \& Heitz-arrest: 
bestuursbesluit definitief is geworden, bijdraagt tot de rechtszekerheid, zodat het Unierecht niet vereist dat een bestuursorgaan in beginsel moet terugkomen op een dergelijk definitief geworden bestuursbesluit."22

Zoals wellicht bekend, is het tevens vaste jurisprudentie van het Hof van Justitie dat het met het effectiviteitsbeginsel verenigbaar is dat in het belang van de rechtszekerheid in het nationale recht redelijke beroeps- en verjaringstermijnen worden gehanteerd die gelden op straffe van verval van de effectuering van het EU-recht, aangezien deze termijnen hun grondslag vinden in het ook in dat recht erkende en gewaarborgde rechtszekerheidsbeginsel. ${ }^{\mathbf{2 3}}$

De hierboven weergegeven vraag wordt vervolgens door het Hof van Justitie bezien in het licht van de bijzondere omstandigheden van de zaak Byankov. Naar het oordeel van het Hof moet zijn eerdere jurisprudentie op dit punt als volgt begrepen:

\begin{abstract}
"Het Hof heeft evenwel in wezen geoordeeld dat een nationaal bestuursorgaan in bijzondere omstandigheden op grond van het in artikel 4, lid 3, VEU vervatte beginsel van loyale samenwerking gehouden kan zijn een definitief geworden bestuursbesluit opnieuw te onderzoeken teneinde meer bepaald rekening te houden met de uitlegging die het Hof nadien aan een relevante bepaling van Unierecht heeft gegeven [...]. Uit de rechtspraak volgt dat het Hof in dit verband rekening heeft gehouden met de bijzonderheden van de situaties en de betrokken belangen teneinde een evenwicht te vinden tussen het vereiste van de rechtszekerheid en het vereiste van de rechtmatigheid uit het oogpunt van het Unierecht [...]."
\end{abstract}

Meer in het bijzonder moet volgens het Hof 'worden nagegaan of in situaties zoals aan de orde in het hoofdgeding, een nationale regeling zoals die welke in de verwijzingsbeslissing is beschreven [artikel $99 \mathrm{APK}$, kan worden gerechtvaardigd door de eerbiediging van het rechtszekerheidsbeginsel, gelet op de gevolgen die daaruit voortvloeien voor de toepassing van het Unierecht en voor de burgers van de Unie tot wie verboden om het grondgebied te verlaten als aan de orde in het hoofdgeding, zijn gericht'. Deze bijzondere omstandigheden maken dat het Hof in deze zaak strijd met het effectiviteitsbeginsel aanwezig acht. Het acht daarbij onder meer doorslaggevend dat het uitreisverbod van 17 april 2007 de in artikel 21 VWEU verankerde vrijheid van Unieburgers te niet doet. Hierbij wordt in aanmerking genomen dat de Bulgaarse wetgeving Byankov geen enkele mogelijkheid biedt om het met deze vrijheid strijdige uitreisverbod te laten heroverwegen, waardoor dat besluit absoluut en voor onbeperkte duur geldt en dus voor onbeperkte duur rechtsgevolgen sorteert. Dit acht het Hof meer specifiek in strijd met artikel 31 van richtlijn 2004/38. Hieruit volgt namelijk de plicht voor de lidstaten om te voorzien in de mogelijkheid van heroverweging van in overeenstemming met het Unierecht opgelegde - in rechte onaantastbare - beperkingen van het vrij verkeer van Unieburgers. Het Hof oordeelt dat een dergelijke mogelijkheid a fortiori moet gelden voor een - in rechte onaantastbare - beperking van het vrij verkeer van Unieburgers die, zoals in de zaak Byankov, in strijd met het Unierecht is vastgesteld. Het voorgaande brengt het Hof tot de conclusie dat de heroverwegingsregeling van artikel 99 APK, die als resultaat heeft dat een - in rechte onaantastbaar - absoluut en voor onbeperkte duur geldend uitreisverbod, dat in strijd met het EU-recht Unieburgers blijvend belet om hun door artikel 21 VWEU verleende recht van vrij verkeer en verblijf uit te oefenen, 'niet redelijkerwijs kan worden 
gerechtvaardigd door het rechtszekerheidsbeginsel en dus in die mate moet worden aangemerkt als strijdig met het doeltreffendheidsbeginsel en met artikel 4, lid 3, VEU'.

\section{Slotopmerking}

Wordt de Nederlandse jurisprudentie bezien waarin de vraag centraal staat of het EU-recht verplicht tot heroverweging van een met dat recht strijdige in rechte onaantastbaar besluit, dan valt op dat deze vraag uitsluitend beantwoord wordt aan de hand van de vier voorwaarden uit het Kühne \& Heitz-arrest. ${ }^{\mathbf{2 4}}$ Daaruit blijkt verder dat de beroepen op dat arrest bijna allemaal struikelen op de tweede voorwaarde, in de zin dat een besluit niet in rechte onaantastbaar is ten gevolge van een uitspraak van een nationale rechterlijke instantie waarvan de beslissingen niet vatbaar zijn voor een gewoon rechtsmiddel, maar ten gevolge van het feit dat tegen een besluit niet (tijdig) de beroepsmogelijkheden zijn doorlopen. ${ }^{\mathbf{2 5}}$ In het Byankov-arrest komt naar voren dat de zojuist weergegeven vraag niet, althans niet uitsluitend, beantwoord moet worden aan de hand van de vier voorwaarden uit het Kühne \& Heitz-arrest, maar binnen het kader van de beginselen van loyale samenwerking (ex artikel 4, lid 3, VEU) en nationale procedurele autonomie, waarbij de beginselen van gelijkwaardigheid en effectiviteit de randvoorwaarden zijn waaraan het nationale recht moet voldoen. Het arrest maakt daarbij duidelijk dat tevens de bijzondere omstandigheden van het geval bepalend zijn voor het aannemen van een dergelijke plicht. In die zin kan tot slot een vergelijking worden gemaakt met het arrest Skoma-lux. ${ }^{\mathbf{2 6}}$ In het bijzondere geval dat aan een particulier een Unierechtelijke regeling vóór de bekendmaking ervan in zijn eigen taal (als officiële taal van Europese Unie) werd tegengeworpen, overwoog het Hof van Justitie in dat arrest dat krachtens het Unierecht een plicht tot het heroverwegen van een in rechte onaantastbare besluiten respectievelijke rechterlijke uitspraken bestaat, in het bijzonder als zij het karakter hebben van een sanctie, indien zij inbreuk maken op fundamentele rechten.

\section{Noten}

1 HvJ 4 oktober 2012, Byankov, C-249/11, n.n.g.; $A B$ 2012/375, m.nt. Widdershoven; $N J$ 2013/56, m.nt. Mok; $J V$ 2012/479, m.nt. Boeles.

2 Het Hof spreekt onder meer over de 'heropening' of 'heronderzoeking' van een besluit met het oog op de mogelijke intrekking ervan. Naar Nederlands recht wordt dan gesproken van 'heroverwegen'. Het heroverwegen sluit niet automatisch in dat een besluit wordt ingetrokken maar er dient dan alleen inhoudelijk bekeken te worden of daarvoor aanleiding bestaat. Zie R. Ortlep, De aantasting van stabiele bestuursrechtelijke rechtsvaststellingen in het licht van het Unierecht, Deventer: Kluwer 2011, p. 15 inclusief verwijzingen.

3 Richtlijn 2004/38/EG van het Europees Parlement en de Raad van 29 april 2004 betreffende het recht van vrij verkeer en verblijf op het grondgebied van de lidstaten voor de burgers van de Unie en hun familieleden. PB L 158, 30 april 2004, p. 77-123.

4 Het Hof verwijst naar verordening (EG) nr. 44/2001 van de Raad van 22 december 2000 betreffende de rechterlijke bevoegdheid, de erkenning en de tenuitvoerlegging van beslissingen in burgerlijke en handelszaken. PB L 12, 16 januari 2001, p. 1-23. 
5 Vergelijk HvJ 10 juli 2008, Jipa, C-33/o7, Jur. 2008, p. I-5157; HvJ 17 november 2011, Gaydarov, C-430/10, n.n.g. Zie H. Oosterom-Staples, 'Het fundamentele recht op vrij verkeer nader bepaald; het arrest Jipa onder de loep', NTER 2009, p. 12-17 inclusief verwijzingen.

6 Vergelijk R. Ortlep 2011, p. 474 e.v. inclusief verwijzingen.

7 HvJ 13 januari 2004, Kühne \& Heitz, C-453/oo, Jur. 2004, p. I-837. Verder HvJ 19 september 2006, i-21 en Arcor, gevoegde zaken C-392/04 en C-422/o4, Jur. 2006, p. I-8559; HvJ 16 maart 2006, Kapferer, C-234/o4, Jur. 2006, p. I2585; HvJ 11 december 2007, Skoma-Lux, C-161/o6, Jur. 2007, p. I-10841; HvJ 12 februari 2008, Kempter, C-2/o6, Jur. 2008, p. I-411.

8 HvJ 19 september 2006, i-21 en Arcor, gevoegde zaken C-392/o4 en C422/o4, Jur. 2006, p. I-8559.

9 R. Ortlep 2011, p. 484 e.v. inclusief verwijzingen.

10 Zie hierover recent A. Adinolfi, "The "Procedural Autonomy" of Member States and the Constraints Stemming from the ECJ's Case Law: Is Judicial Activism Still Necessary?', in: H.-W. Micklitz \& B. de Witte (eds.), The European Court of Justice and the Autonomy of the Member States, Cambridge: Intersentia 2012, p. 281-303; M. Bobek, "Why There is No Principle of "Procedural Autonomy" of the Member States', in: H.-W. Micklitz \& B. de Witte (eds.), The European Court of Justice and the Autonomy of the Member States, Cambridge: Intersentia 2012, p. 305-323; R. Ortlep \& M.J.M. Verhoeven, 'Collisions between EU law and national law', in: H.R.B.M. Kummeling et al. (eds.), De samengestelde Besselink. Bruggen bouwen tussen nationaal, Europees en internationaal recht, Oisterwijk: WLP 2012, p. 173-186 inclusief verwijzingen.

11 Vergelijk A-G Mengozzi voor HvJ 4 oktober 2012, Byankov, C-249/11, n.n.g.

12 Zie P.H.P.H.M.C. van Kempen, Heropening van procedures na veroordelingen door het EHRM, Nijmegen: WLP 2003 inclusief verwijzingen.

13 Vergelijk L.A.D. Keus, 'Ontwikkelingen binnen de Europese Unie op het gebied van de rechtspraak', Trema 2004, p. 435-441; L.A.D. Keus, 'Reparatie van met het internationale recht conflicterende uitspraken', in: S. Dumoulin (red.), De vader van de gedachte, Nijmegen: WLP 2003, p. 137-147.

14 Vergelijk Widdershoven onder HvJ 4 oktober 2012, Byankov, C-249/11, n.n.g.; $A B$ 2012/375.

15 A-G Mengozzi voor HvJ 4 oktober 2012, Byankov, C-249/11, n.n.g.

16 P.H.P.H.M.C. van Kempen, 'Redres bij schending Eurostrafrecht', NTER 2005, p. 164-175.

17 P.H.P.H.M.C. van Kempen 2005, p. 168.

18 Vergelijk HvJ 26 februari 2013, Åkerberg Fransson, C-617/10, n.n.g.; HvJ 26 februari 2013, Melloni, C-399/11, n.n.g.; HvJ 21 december 2011, NS, gevoegde 
zaken C-411/10 en C-493/10, n.n.g.; HvJ 13 september 2011, Prigge, C-447/o9, n.n.g.; HvJ 6 september 2011, Patriciello, C-163/10, n.n.g.; HvJ 22 december 2010, DEB, C-279/o9, Jur. 2010, p. I-13849; HvJ 14 oktober 2010, Fuß, C243/o9, Jur. 2010, p. I-9849. Zie H. Kaila, 'The Scope of Application of the Charter of Fundamental Rights of the European Union in the Member States, in: P. Cardonnel et. al. (eds.), Constitutionalising the EU Judicial System, Oxford: Hart Publishing 2012, p. 291-315; T. Nauta, 'De inroepbaarheid van het Handvest voor de Europese en nationale rechter', NTER 2012, p. 19-25; A. Pahladsingh en H.J.Th.M. van Roosmalen, 'Het Handvest van de grondrechten van de Europese Unie twee jaar juridisch bindend: rechtspraak in beweging?', NTER 2012, p. 56-65; A. Pahladsingh en H.J.Th.M. van Roosmalen, 'Het Handvest van de Grondrechten van de Europese Unie één jaar juridisch bindend: rechtspraak in kaart', NTER 2011, p. 54-61 inclusief verwijzingen.

19 Vergelijk T. Barkhuysen en A.W. Bos, 'De betekenis van het Handvest van de Grondrechten van de Europese Unie voor het bestuursrecht', JBplus 2011, p. 334 inclusief verwijzingen.

20 Vergelijk HvJ 13 januari 2004, Kühne \& Heitz, C-453/oo, Jur. 2004, p. I837; HvJ 16 maart 2006, Kapferer, C-234/04, Jur. 2006, p. I-2585. Zie R. Ortlep, 'Geen bevoegdheid = Geen verplichting! Enkele gedachten over de uitspraak van het Hof van Justitie in de zaak Kapferer', NTER 2006, p. 138-140; A-G Bot voor HvJ 12 februari 2008, Kempter, C-2/o6, Jur. 2008, p. I-411; H. Juntunen, Die Einwirkungen des Gemeinschaftsrechts auf die Bestandskraft von Verwaltungsakten und die Rechtskraft von Gerichtsurteilen, Berlin: WVB 2009, p. 233 e.v.; D.U. Galetta, Procedural Autonomy of EU Members States: Paradise Lost?, Heidelberg: Springer 2010, p. 56; J.M. Baumann, Die Rechtsprechung des EuGH zum Vorrang von Gemeinschaftsrecht vor mitgliedstaatlichen Verwaltungsakten und Gerichtsurteilen, Frankfurt am Main: Peter Lang 2010, p. 131 e.v. inclusief verwijzingen.

21 Vergelijk HvJ 14 december 1995, Van Schijndel, gevoegde zaken C-430/93 en C-431/93, Jur. 1995, p. I-4705; HvJ 14 december 1995, Peterbroeck, C-312/93, Jur. 1995, p. I-4599; HvJ 21 november 2002, Cofidis, C-473/oo, Jur. 2002, p. I10875; HvJ 8 september 2011, Rosado Santana, C-177/10, n.n.g.

22 HvJ 13 januari 2004, Kühne \& Heitz, C-453/oo, Jur. 2004, p. I-837. Verder HvJ 19 september 2006, i-21 en Arcor, gevoegde zaken C-392/O4 en C-422/o4, Jur. 2006, p. I-8559; HvJ 16 maart 2006, Kapferer, C-234/o4, Jur. 2006, p. I2585; HvJ 12 februari 2008, Kempter, C-2/o6, Jur. 2008, p. I-411.

23 Vergelijk HvJ 24 maart 2009, Danske Slagterier, C-445/o6, Jur. 2009, p. I2119; HvJ 6 oktober 2009, Asturcom Telecomunicaciones, C-40/o8, Jur. 2009, p. I-9579; HvJ 27 oktober 2009, Pontin, C-63/o8, Jur. 2009, p. I-10467; HvJ 21 januari 2010, Alstom Power Hydro, C-472/o8, Jur. 2010, p. I-623; HvJ 19 mei 2011, Iaia, C-452/o9, n.n.g.; HvJ 18 oktober 2012, Pelati, C-603/10, n.n.g.

24 Vergelijk de jurisprudentie genoemd in de volgende voetnoot.

25 Vergelijk CBB 15 februari 2013, LJN: BZ4423; Rb. 's-Gravenhage 9 januari 2013, LJN: BZoo45; CRvB 28 september 2012, LJN: BX9398; CRvB 28 september 2012, LJN: BX9420; CRvB 4 mei 2011, LJN: BQ3857; CRvB 6 januari 2011, LJN: BPo348; Gerechtshof Arnhem 20 april 2010, LJN: BM4329; 
Gerechtshof 's-Hertogenbosch 20 mei 2009, LJN: BJ3815; CBB 19 juni 2008, LJN: BD5032; CBB 19 juni 2008, LJN: BD5034; CRvB 6 november 2008, LJN: BG5037; CBB 28 november 2007, LJN: BB9712; HR 5 oktober 2007, LJN: AZ9098; CRvB 28 april 2006, LJN: AX1265; CRvB 4 januari 2006, LJN: AU9156; CBB 22 september 2004, LJN: AR3073; CRvB 29 april 2004, LJN: $\mathrm{AO} 9462$.

26 HvJ 11 december 2007, Skoma-Lux, C-161/o6, Jur. 2007, p. I-10841. Zie H. van Eijken en M.J.M. Verhoeven, 'Lost in translation. Een bespreking van het arrest Skoma-Lux: de doorwerking van niet officieel gepubliceerde verordeningen', NTER 2008, p. 165-171 inclusief verwijzingen. 